\title{
Nueva edición bilingüe español-inglés
}

\author{
New bilingual edition spanish-english
}

Desde estas mismas líneas y en anteriores editoriales se ha señalado la importancia que hoy en día tiene el mundo de las comunicaciones. Parece que estamos "traspasando la puerta de entrada" al mundo de la globalización de la información vía electrónica, y las revistas científicas han de adaptarse a esta nueva tendencia. Por supuesto que, de momento, debemos de seguir potenciando las ediciones en papel, aunque en el fondo todos sabemos que en un futuro no muy lejano, los pesados volúmenes bibliográficos serán sustituidos por livianas ediciones en formato CD-rom o incluso "virtuales", a través de la red.

De lo que no cabe duda, es de que, a pesar de las innovaciones tecnológicas, el mundo y los seres humanos que nos manejamos en la red, estamos obligados a hablar un mismo idioma, y nos guste o no, ese idioma tiene un nombre propio: el inglés. Es previsible que en el futuro las diferencias existentes entre esta lengua y las demás se incrementen, y también hay que pensar que esto no necesariamente significa que sea malo. Está claro que cada país luchará por su lengua, pero ante el inglés, todos tenemos la batalla perdida. Hay que recordar que tras este idioma, otros hablados por gran cantidad de seres humanos no tienen apenas relevancia, como el chino o el ruso; incluso lenguas clásicas (que no antiguas) como el alemán, el italiano o el japonés tienen muy poca relevancia en el mundo científico. Posiblemente el español, también llamado castellano, sea el segundo idioma en importancia científica estando al mismo nivel del francés o del portugués.

Pues bien, una vez que "hemos perdido la batalla" del idioma, no nos cabe más que "unirnos al vencedor". Por ello, la Rev Esp Cirug Oral y Maxilofac estrena hoy una nueva edición bilingüe, en español y en inglés, de tal modo que pueda ser leída en cualquier lugar del planeta. A pesar de esta aparente "anglosajonización", la dirección de esta revista no va a descuidar en absoluto la edición en español, y seguiremos haciendo con esmero las correcciones de estilo pertinentes para publicar los artículos en el mejor castellano posible, integrando el creciente aumento de artículos provenientes de los países hermanos Latinoamericanos y sus peculiares "giros" linguísticos. Esta nueva edición bilingüe ha sido posible gracias a una beca, solicitada por la Junta Directiva de la Sociedad Española de Cirugía Oral y Maxilofacial (SECOM) así como por la dirección editorial de la revista, y concedida por el FIS (Fondo de Investigaciones Sanitarias) del Instituto de Salud Carlos III, que nos ha permitido cubrir los elevados gastos que la traducción y la edición de la revista en color, conllevan. Esto, posiblemente facilitará la difusión de nuestro órgano científico oficial en todo el mundo, e incluso tratar de nuevo de conseguir el ansiado Index Medicus.

Además, tal como publicamos en el anterior número, SciELO (Scientific Electronic Library Online), ha incluido nuestra revista en su base de datos como publicación electrónica. Desde hoy ya se puede consultar en su web: www.scielo.org o directamente en la dirección específica para nuestra revista: $\mathrm{http}$ ://scielo.isciii.es/scielo.php?script= sci_serial\&pid=1130-0558\&lng=es\&nr. La página es sencilla de utilizar, e incluye un práctico buscador, por artículos, temas y autores. Animamos a todos los lectores a emplear esta vía de difusión. 